\title{
EDUCACIÓN MEDIÁTICA EN MÉXICO: DE LA VULNERABILIDAD Y RIESGOS ENTRE USUARIOS DE REDES SOCIALES
}

Genaro Aguirre Aguilar'

Universidad Veracruzana, México geaguirre@uv.mx

Recibido: 16/3/19/ Aceptado: 24/6/19

doi: $10.26439 /$ contratexto2019.n032.4617

Resumen. La fragilidad y la vulnerabilidad que han observado algunas prácticas y hábitos frente al consumo mediático y el uso de las tecnologías por parte de los mexicanos obliga a la discusión sobre la ausencia de políticas educativas orientadas a la educación en medios y la alfabetización digital; un asunto que, históricamente, ha estado pendiente en la agenda pública y entre las comunidades académicas en los últimos años. Este artículo parte de una experiencia vivida en el estado de Veracruz, que desencadenó una serie de eventos reveladores de la vulnerabilidad en el consumo y uso de las TIC que afecta a sus ciudadanos. Para ello se recuperan algunos aspectos teóricos que contribuyen a dimensionar la importancia de educar en medios y en el uso responsable de las tecnologías en un país como México, pues situaciones afines a aquella experiencia siguen presentándose hasta nuestros días, con resultados lamentables.

Palabras clave: educación mediática / medios de comunicación / alfabetización digital / TIC / redes sociales

1 Doctor en Sociedades Multiculturales por la Universidad Veracruzana, México. https://orcid.org/00000001-5223-9783 


\section{MEDIA EDUCATION IN MEXICO: VULNERABILITY AND RISKS AMONG SOCIAL NETWORK USERS}

Abstract. The fragility and vulnerability caused by some practices and habits in the face of media consumption and the use of technologies by Mexicans lead to discuss the absence of educational policies aimed at media education and digital literacy: an issue that has historically been pending in the public agenda and among academic communities in the past few years. This article starts from an experience lived in the state of Veracruz, which triggered a series of events unveiling the vulnerability in the consumption and use of ICTs that affects its citizens. Thus, some theoretical aspects that contribute to seize the importance of media education and the responsible use of technologies in a country like Mexico are recovered, since events related to such experience still occur nowadays with poor results.

Keywords: Media education / media / digital literacy / ICT / social networks

\section{EDUCAÇ̃̃O PARA A MÍDIA NO MÉXICO: VULNERABILIDADE E RISCOS ENTRE USUÁRIOS DE REDES SOCIAIS}

Resumo. A fragilidade e vulnerabilidade que têm sido observadas em algumas práticas e hábitos, perante o consumo das mídias e o uso das tecnologias dos mexicanos, obrigam a realizar uma discussão sobre a ausência de políticas educacionais voltadas para a educação midiática e a alfabetização digital; uma questão que, historicamente, tem sido relegada das políticas educacionais e das discussões de acadêmicos e pesquisadores nos últimos anos. 0 objetivo deste artigo é partir de uma experiência empírica vivida no estado de Veracruz, que suscitou uma série de eventos que revelam a vulnerabilidade no consumo e uso das TIC por seus cidadãos. Para isso, se recuperaram alguns aspectos teóricos que contribuem a dimensionar a importância de educar na mídia e no uso responsável de tecnologias em um país como o México, uma vez que eventos relacionados a essa experiência continuam apresentando-se até hoje com resultados lamentáveis.

Palavras chave: Educação midiática / meios de comunicação / alfabetização digital / TIC / redes sociais 


\section{INTRODUCCIÓN}

Aquel 25 de agosto del 2011 en el puerto de Veracruz, México, los padres de familia se aprestaban a llevar a sus hijos al colegio. Otros se dirigían a sus labores cotidianas. Como de costumbre, la TV local, las plataformas informativas y las redes sociales informaban del acontecer noticioso. En esta ciudad, los ciudadanos habían encontrado en las redes sociales los canales para favorecer el seguimiento y cobertura de noticias violentas que los medios tradicionales, por petición oficial, regularmente no reportaban. Particularmente a través del \#verfolow, una ciudadanía organizada rompía con el cerco informativo impuesto por el gobierno estatal, en aquellos días en que la violencia encabezada por el crimen organizado tomó por asalto el espacio público.

A media mañana, un rumor comenzó a circular en WhatsApp y Facebook: comandos armados estaban levantando niños en las escuelas de la ciudad, mientras que otros reportes hablaban sobre supuestos enfrentamientos entre bandas criminales y el ejército mexicano que, como parte de la estrategia federal en la guerra contra el narco, patrullaba las calles porteñas. El resultado fue una psicosis colectiva que llevó a decenas de padres de familia a salir con urgencia para recoger a sus hijos. En los colegios, ante la ausencia de protocolos para situaciones de crisis como esta, se generó un caos que desnudó la vulnerabilidad social que se tiene frente al inapropiado uso de las tecnologías móviles y el papel que juegan las redes sociales en la difusión de lo que hoy conocemos como fake news. Accidentes viales, crisis nerviosas, crispación ciudadana, histeria colectiva fueron parte de un fenómeno que se reproduciría en otras ciudades del estado.

Aquella experiencia no solo hizo visible las angustias, los miedos, las incertidumbres, los demonios de una sociedad en el contexto de la guerra contra el narcotráfico que encabezara el gobierno de Felipe Calderón, sino también la ausencia de un uso razonable y crítico de una tecnología incorporada a la vida cotidiana que, en las redes sociales virtuales, encontró un recurso para socializar, producir o difundir información con extrema facilidad.

Si bien la referencia que se toma para situar el objeto de estas reflexiones tiene 8 años, es importante señalar que eventos afines a este han venido sucediendo en el último lustro, como resultado de ese cuarto lugar mundial que ocupa México con sus 63 millones de usuarios con perfil en redes sociales. Esta situación permite comprender -en voz de Hernández Audelo- lo que hoy serían riesgos novedosos que vive el usuario de redes sociales, al ampliarse las posibilidades de agresión y vulnerabilidad por el tipo de contenido que se publica, donde prácticamente "se les da información completa a los criminales para victimizar a los usuarios" (México, cuarto lugar a escala mundial en el uso de redes sociales, 2018, párr. 5).

Sobre la vulnerabilidad, Dilcya Samantha García Espinoza de los Monteros, subprocuradora para la Atención de Delitos Vinculados a la Violencia de Género de la Procuraduría 
General de Justicia del Estado de México (PGJEM), señala que con las redes sociales se incrementó el número de desapariciones de niños y adolescentes. Sostiene que, en más de $90 \%$ de casos en que se ha activado la Alerta Amber para localizar a niños y adolescentes en el Edomex, desde el 2013, se tiene registrado que los menores avisaron en sus cuentas que escaparían o que conocieron a alguien por internet o mandaron pistas (Notimex, 2016, párr. 3). Se complementa la información con un dato alarmante: de las 475 Alertas Amber emitidas aquel año, el $90 \%$ de los involucrados usaron internet.

Junto con experiencias de este tipo se tendrían que sumar otras prácticas delincuenciales, por ejemplo, las relacionadas con las extorsiones telefónicas, para lo cual se dice que del 2012 al 2018 tuvieron un incremento del 90 \% (Steve, 2018). Según información del portal de la Policía Federal en México, en el año 2000 se disparó este delito, debido a que el uso del teléfono celular se masificó y llegó a mayores sectores de la población.

Otra estrategia para obtener información es analizar imágenes divulgadas en redes sociales, lo que les permite conocer el nivel socioeconómico de la posible víctima y su familia. Luego obtienen el número del teléfono celular de la víctima, utilizando argumentos relacionados con las actividades o intereses de la posible víctima, o bien, ofertando una posición laboral. (Policía Federal, 2019, párr. 8)

Lo anterior lleva a reconocer la necesidad de promover una educación en medios que contribuya al desarrollo de competencias mediáticas para favorecer una alfabetización digital frente a las nuevas experiencias de socialización mediada por dispositivos móviles y que posibilite la constitución de una ciudadanía habilitada para responder a los dilemas que caracterizan al siglo xxı.

Novedosas prácticas delincuenciales, como la experiencia vivida en Veracruz, marcan un punto de quiebre para reflexionar sobre la necesidad de ser conscientes y vigilantes de la forma en que se emplean las tecnologías, y se consume y distribuye contenido. Estos aspectos llevan a presentar un texto que, desde la experiencia de un país como México y en el caso particular del estado de Veracruz, problematiza y reflexiona sobre la ausencia de una educomunicación que genere conciencia crítica y creativa entre los mexicanos para inhibir o prevenir experiencias como la vivida también en enero del 2017, cuando a través de redes sociales se convocó a protestar por el incremento en los combustibles. En pocas horas, sectores ciudadanos salieron a las calles para vandalizar comercios, haciendo del saqueo a tiendas comerciales un acto de barbarie que exhibía - una vez más - lo vulnerable del ciudadano común. En estados como Quintana Roo, Chiapas, Michoacán, Hidalgo, Tamaulipas, Sonora, Querétaro, Morelos, la Ciudad de México y Veracruz se demostró la falta de conciencia de decenas de ciudadanos, que respondieron a un llamado en redes sociales para delinquir.

En este contexto, el texto indaga teóricamente sobre la comunicación mediática, ubica tensiones en la relación de la comunicación con la educación, refiere aspectos 
sobre política educativa en México, para pasar a la alfabetización mediática y la domesticación que han hecho de las tecnologías los usuarios mexicanos. El recorrido que permite tener una referencia para abordar problemáticas que se han vivido en este país por el tipo de prácticas y hábitos que en el uso de los dispositivos móviles y las redes sociales observan los ciudadanos.

\section{DESARROLLO}

\section{a. Comunicación mediática, su estudio y el desarrollo tecnológico hoy}

Los estudios en comunicación en lberoamérica observaron un giro en el foco que caracterizaba su atención hacia finales de los 80 tras la aparición del libro de Jesús Martín-Barbero, De los medios a las mediaciones (2003) (reconocido en la edición conmemorativa por sus 30 años, en la que especialistas disertan sobre los aportes de aquella obra), en el que la dimensión social, cultural y educativa complejiza las formas en que se había problematizado la relación medios de comunicación y sus públicos. Los modelos teóricos que focalizaban los grados de impacto del emisor y sus mensajes en el receptor comenzaron a replantearse para determinar la viabilidad o pertinencia de este tipo de abordajes, en virtud de la dificultad que representa confirmar o comprobar grados de influencia mediática, frente a la heterogeneidad de variables que definen la experiencia de recepción de las personas: el concepto de mediación deviene en categoría que redimensionó el estudio de los fenómenos comunicativos mediáticos.

Sobre esto, Enrique Bustamante señala que, en aquel entonces, hacía falta vincular los medios de comunicación a la cultura, empecinados como estábamos con un "funcionalismo obsesivo sobre los efectos de los medios o el determinismo tecnológico reinantes desde autores estadounidenses y sus epígonos europeos y españoles", invisibilizando los contenidos transmitidos, así como "el papel de los usuarios, etc." (2017, p. 103); en especial, aquello relacionado con "los contenidos simbólicos que los medios producían y reproducían de forma sistemática y mayoritaria en la sociedad" (p. 103). Al modelo tradicional, emisor-mensaje-receptor, se sumaron otros elementos para reconocer la densidad y complejidad del fenómeno comunicativo.

De investigaciones centradas en lo más mediático se llegaría a una dimensión educativa, primero en medio de tensiones o desencuentros que, sostiene De Fontcuberta, eran provocados por "criterios divergentes a la hora de conceptualizar y delimitar el espacio académico de la comunicación y la educación" cuyo segundo momento se caracterizó por las "distintas perspectivas en la aplicación práctica de sus supuestos teóricos" (2001, pp. 141-142).

En lo educativo, el interés residía en las formas de empleo o apropiación de los medios de comunicación, radio, TV, prensa, cine, como recursos que contribuían al 
proceso de enseñanza-aprendizaje, pero también en reconocimiento al poderoso vínculo de los medios masivos de comunicación (MMC) con la sociedad, para que, más tarde, la concepción se complejizara, pues, como apunta Georgina Amayuela Mora, la educación es "un proceso comunicativo dialógico, [donde se dan] las relaciones horizontales entre docentes y discentes" (2017, pp. 9-10), donde el aula es un espacio para el encuentro de subjetividades.

En plenitud de la globalización María Teresa Quiroz sostenía: “En el mundo actual se comparte un conjunto de objetos que han perdido su sentido de localización y cuyas referencias sociales se han desenraizado y han pasado a formar parte de imaginarios comunes" (1997, p. 32). En aquel entonces, las nacientes tecnologías digitales ya se revelaban como medios a través de los cuales se narraba y se representaba el mundo, comenzaban entonces a ser agencias y espacios de legitimidad, tan cercanos a lo que la escuela ha representado, por la forma en que promueven mecanismos de socialización (Quiroz, 1997). En el contexto de la sociedad de la información y del conocimiento, este desarrollo tecnológico hoy constituye "un nuevo lenguaje, pues se está viviendo un cambio estructural y de paradigmas que están modificando los fundamentos de la sociedad y abriendo paso a otra, que implica nuevas formas de comprensión e interpretación de la realidad" (Balart Carmona y Cortés Fuentealba, 2018, p. 4). Con esto, el profundo reto de educar, pero también explicar el papel que tienen los medios de comunicación y las tecnologías en la construcción de narrativas que definen un paisaje que hay que aprender a decodificar.

En tal contexto, es posible reconocer experiencias en España y Latinoamérica que han constituido perspectivas sobre la forma de entender la comunicación mediática y su vínculo con la educación; y aun cuando es posible aceptar que hay tareas pendientes, tal discusión académica es una experiencia ausente en México, cuyo resultado es una escasa o nula educación mediática, sostienen Orozco Gómez y Corona Berking, quienes durante la presentación de la Cátedra Unesco: Alfabetización Mediática e Información y Diálogo Intercultural (MILD), coincidieron en señalar: "Los mexicanos no sabemos interpretar lo que muestran u ocultan los medios electrónicos (televisión, internet), tampoco conocemos que tenemos el derecho de apelar a estos medios de comunicación o utilizar internet como una forma de educarnos" (González, 2015, párr. 1), no únicamente para consumir.

El interés por el empleo de recursos audiovisuales como dispositivos para mediar en el aprendizaje estudiantil que vinculara la comunicación con la educación devino en la educomunicación: la formación en el conocimiento, la comprensión de los lenguajes técnicos que caracterizan las narrativas y códigos que definen el lenguaje en la prensa, la radio, el cine y la TV (Ramírez García, Renés Arellano y González Fernández, 2016); una experiencia que permite a niños, adolescentes o jóvenes adquirir competencias audiovisuales y mediáticas, entendidas básicamente como "el conocimiento de los medios de comunicación y de las tecnologías multimedia" (Acosta-Silva, 2017, p. 493). 
A partir de los 90, el interés de la academia para explicar o comprender las relaciones emergentes entre los usuarios y las tecnologías digitales, diversificó los abordajes metodológicos. Del predominio positivista vino el abordaje sociocrítico, dialéctico como fenomenológico. Con esto, la visibilidad y concepción teórica de nuevos agentes de mediación e interpelación del ciudadano.

Los medios convencionales comenzaron a observar un sacudimiento: el cine con la llegada de los videorreproductores caseros, la radio con las nuevas formas de reproducción sonora (del discman a los reproductores de MP3), la prensa frente a los portales informativos y el papel de las redes sociales; crisis que hoy vive la televisión convencional ante las ofertas en streaming, que repercuten tanto en los modelos de negocios como en las experiencias de consumo de las personas.

Un nuevo paisaje mediático se constituye, sobre todo, con la llegada del internet, los dispositivos móviles y las formas de producción de contenidos multimodales y multicanal: "La multimodalidad se refiere a las diversas tecnologías de comunicación. Multicanal se refiere a la disposición organizativa de las fuentes de comunicación" (Castells, 2012, p. 183). Como señala Rosalía Winocur, si bien el acceso a internet no garantiza igualdad de oportunidades para consumir sus contenidos, sí permite que el "capital cultural y simbólico y los procesos de socialización tecnológica de jóvenes de diversa pertenencia sociocultural" (2009, p. 53) favorezcan el acuñamiento de heterogéneas experiencias de apropiación de las tecnologías.

Por su parte, las empresas dedicadas a la producción de contenidos (analógicos como digitales), según Manuel Castells, emplean las TIC con novedosas maneras de gestión de contenidos, tomando como plataforma la conexión en red, esto "para personalizar sus mensajes dirigidos a audiencias concretas, al tiempo que proporcionan un canal para el intercambio global de manifestaciones culturales locales" (Castells, 2012, p. 188). Sin embargo, los servicios que la TV y las plataformas digitales ofrecen para el ocio, el entretenimiento y la diversión no se limitan a presentar una realidad, también la representan, buscan una intencionalidad o, como aseguran Ambròs y Breu: "Escogen, seleccionan, convierten hechos en historias, crean personajes, nos invitan a ver el mundo de una manera determinada. Los medios nos ofrecen versiones de la realidad, pero nunca es la realidad" (2011, p. 25).

Y esto, regularmente no lo tiene dimensionado ni comprendido el usuario común, pues, como lo afirma Corona Berking (2015), aun cuando la Secretaría de Educación Pública (SEP) ha dado cabida a la comunicación y las TIC, sus propuestas han sido poco exitosas. En ese contexto, con relación a las habilidades que deben promover los profesores mexicanos entre sus estudiantes, Forbes habla de promover "el lenguaje multiplataforma, el trabajo colaborativo, las habilidades de búsqueda y discriminación de información [en] la web, la conectividad permanente, el desarrollo de contenidos 
nativos y la ética en el uso de la red" (Vázquez, 2018, párr. 10); acciones y temáticas que, sin duda, abonan a la educación mediática como a la alfabetización digital.

La necesidad para que nuestros jóvenes estudiantes reconozcan la importancia de saber desde dónde se construye un mensaje, su objetivo comercial, político e ideológico que definen sus narrativas, son algunas premisas que deben acompañar su formación; por lo que es urgente que la educación en México coloque en su agenda la alfabetización mediática y digital en los términos que la Unesco lo plantea: "Comprender y utilizar los medios de masas de forma segura [...], incluyendo un conocimiento informado y crítico de los medios y de las técnicas que los medios emplean y sus efectos" (Unesco, 2011, p. 185).

Si bien se está lejos de pensar en relaciones horizontales entre emisores y receptores, los usuarios han dejado la pasividad para ser productores y difusores de contenidos, lo que no exime promover acompañamientos educativos para el uso razonable, responsable y seguro de las TIC. No se trata de que se pierda el sentido y significado de lo que han logrado los usuarios en su relación con los medios de comunicación y las tecnologías, como lo plantean Alba Ambròs y Ramon Breu, se trata de que los jóvenes se capaciten para decidir por cuenta propia, pero con conocimiento de causa, sin que pierdan "el gusto estético y fascinante del medio. Más que protección, hay que optar por la preparación" (2011, p. 24). Se trata de que la sociedad recree una experiencia de consumo consciente y responsable ante lo ideológico o político de las narrativas mediáticas.

Si bien es pertinente el cambio de paradigma que promueven los países y las instituciones educativas con relación a la incorporación de las tecnologías a los procesos de enseñanza-aprendizaje, el objetivo es desarrollar competencias digitales para habilitar a los jóvenes en los saberes, destrezas y actitudes para enfrentar los retos del presente siglo, habrá que pasar de lo instrumental a lo cognitivo, para coadyuvar en una alfabetización que trascienda su experiencia de consumidor o productor a un sujeto epistémico capaz de distinguir los atributos ideológicos, discriminatorios, estigmatizantes de muchas de las narrativas que se observan en las plataformas digitales, las redes sociales, los servicios de mensajería instantánea como en los MMC.

Educar en medios para una cultura digital obliga a las instituciones y sus académicos a reconocer el valor que tienen las TIC como herramientas innovadoras; sin embargo es primordial que se dimensione el papel que puede jugar la educomunicación, para que las nuevas generaciones comprendan que es importante el manejo de las tecnologías, pero también de sus contenidos, por lo que, al hablarse de alfabetismo mediático, también se exige considerar las competencias digitales (Li y Ranieri, 2010). La Unesco plantea una premisa:

Dotar a los ciudadanos de los conocimientos básicos sobre el papel de los medios de comunicación y los dispositivos de información en las sociedades democráticas, siempre que esa función esté correctamente desempeñada y los 
ciudadanos puedan evaluar de forma crítica la calidad de los contenidos que se transmiten. (s/f, p. 5)

El organismo sostiene que la alfabetización mediática e informacional es una suerte de requerimiento (incluso atributo) que debe ser parte del derecho de las personas, de la gente, al asegurar que es "indispensable para el ejercicio del derecho individual a comunicarse, a expresarse y a buscar, recibir y transmitir información e ideas" (s/f, p. 2).

Como puede reconocerse, el interés por los medios de comunicación, las TIC y su alfabetización ha transcendido para configurar un fenómeno donde los científicos sociales han permitido la articulación de una serie de constructos que amplían el horizonte desde el cual problematizar, explicar o comprender la relación entre el ser humano y la tecnología, para lo cual la comunicación y la educación deben erigirse como formadoras de ciudadanos alfabetizados mediática y digitalmente.

Sociedades del conocimiento, Web 2.0, educación en medios, competencias digitales, educación mediada por TIC, alfabetización digital, entre otros, son constructos que nombran teóricamente lo que observa nuestra sociedad actual. Lo cierto es que en muchos casos son concepciones cuya aplicabilidad académica no siempre encuentra resonancias en las prácticas y hábitos que tienen las personas.

Es por esto que se requiere una educación en medios que promueva entre las nuevas generaciones el desarrollo de una alfabetización mediática y digital que favorezca un pensamiento crítico, responsable, creativo y consciente, frente a las tecnologías desde las que se vinculan, representan y socializan en el mundo de hoy, pero también para que se comprenda que detrás de las narrativas que caracterizan el paisaje mediático, hay intenciones, hay representaciones; posturas políticas, ideológicas, comerciales que deben aprender a decodificar, tomando conciencia y lo que está detrás de ellas.

\section{b. De políticas educativas y alfabetización mediática en México}

En el caso de México, el Modelo Educativo para una educación obligatoria. Educar para la libertad y la creatividad (Secretaría de Educación Pública, 2017), al hablar de los desafíos de la sociedad del conocimiento, precisa en su documento: "Si bien en la sociedad actual la transmisión de la información y la producción de nuevos saberes ocurren desde ámbitos diversos", corresponde a las instituciones educativas "asegurar que todas las personas tengan la posibilidad de disfrutar de sus beneficios; y crear las condiciones para adquirir las habilidades de pensamiento cruciales en el manejo y procesamiento de información y uso consciente y responsable de las TIC" (Secretaría de Educación Pública, 2017, p. 32).

El impulso a este tipo de políticas educativas con inclusión de las tecnologías, sin duda se alinea con las propuestas que han hecho organismos como la OEI (2009), la Unesco 
(2013), la OCDE (2017), la Cepal (2016), Fundación Telefónica (2017), así también autores como Coll (2008), Tedesco (2008), entre otros, quienes han destacado la pertinencia para formar a las actuales generaciones con una perspectiva crítica y responsable, donde las tecnologías puedan ser recursos que medien en los aprendizajes. A partir de aquí, los ministerios de Educación de los países hispanohablantes han desarrollado políticas para fortalecer el vínculo entre la comunicación mediática y tecnológica con lo educativo, definiendo modelos pedagógicos para una alfabetización digital.

En el documento rector de la reforma educativa impulsada por Enrique Peña Nieto (hoy derogada por el presidente Andrés Manuel López Obrador), al hablarse de las habilidades digitales que definan el perfil de egreso de los estudiantes de enseñanza media superior, se destaca del valor que tienen las TIC: "para investigar, resolver problemas, producir materiales y expresar ideas", donde el estudiante debe ser un sujeto capaz de aprovechar "estas tecnologías para desarrollar ideas e innovaciones" (Secretaría de Educación Pública, 2017, p. 52), por lo que el profesorado debe desarrollar habilidades comunicativas y tecnológicas.

Declarado así, se comprende el rol que puede jugar la alfabetización digital como un derecho confesado o natural de los estudiantes para enfrentar con responsabilidad y postura crítica los MMC, las TIC y sus narrativas, en el entendido de que una alfabetización se relaciona con las audiencias.

La alfabetización mediática [...] representa una serie de facultades encarnadas en las audiencias que suponen una radical contestación a las relaciones inequitativas de poder en el ecosistema mediático que privilegian a los concesionarios, al órgano regulador, a los poderes de la unión e incluso a la figura del defensor de las audiencias por encima de las audiencias. (Méndez Forssell, 2017, párr. 12) Si estos planteamientos repercuten en el mundo académico, es de reconocer el esfuerzo que realizan los docentes, quienes vienen reinventando sus prácticas pedagógicas, a cuyos conocimientos se han sumado el uso y la resignificación de las tecnologías con fines educativos. En ese contexto, los estudiantes han visto enriquecidas las actividades áulicas con la incorporación de recursos tecnológicos. Pero también, como generación, observan un cambio en la relación que pueden tener con el mundo, a través de una mediación que deslocaliza lugares para el aprendizaje; experiencia igualmente compartida por profesores y adultos que deviene en "prácticas mediáticas que tienen una naturaleza sociocultural, y son capaces de mediar y ser mediadas por otras prácticas y lógicas culturales". (Padilla de la Torre, 2012, p. 32)

Con esto, se está ante un tipo de usuario acostumbrado a moverse en un mundo altamente tecnológico, lo que lo supondría conocedor y diestro en potenciar desde una posición crítica el empleo de las tecnologías de las que hoy dispone. ¿Pero esto supone una alfabetización o apenas representa algunas destrezas digitales como lo plantea la Secretaría de Educación Pública? 
La domesticación de la tecnología se relaciona con una habilitación, pero también con usos y hábitos que despliegan los usuarios, revelando ángulos de vulnerabilidad ante la ausencia de una educación mediática y digital, resultado del empleo poco reflexivo para acceder a internet y los medios que emplean los internautas, particularmente jóvenes.

Del crecimiento exponencial de las fake news al sexting, de la publicación de información confidencial a la sobrexposición de contenidos violentos; de movimientos ciudadanos solidarios a la cultura conspiracionista, el crecimiento de grupos radicales o fundamentalistas; de la producción de tutoriales informativos al culto de youtubers e influencers; de un público acostumbrado a seguir las telenovelas y series semanales a las nuevas experiencias a través del streaming; de la solidaridad ciudadana a extraordinarias prácticas de discriminación e intolerancia, se está ante nuevos perfiles de usuarios, quienes no solo consumen, también producen y distribuyen contenidos; deciden formas novedosas de entretenimiento y diversión, de representación y narración de realidades, experiencias en las que, invariablemente, los medios de comunicación y las tecnologías son agencias mediadoras en este nuevo mundo de posibilidades.

Junto a estos atributos y la condición desde la que se es usuario de las tecnologías y consumidores de narrativas mediáticas, se coincide con Buckingham cuando cuestiona el papel bondadoso asignado a los nuevos medios digitales, ya que si bien los públicos usuarios tienen un rol activo al estar habilitados para discriminar y ser críticos, es importante reconocer "que algunos hechos no son del todo conocidos acerca de los medios digitales y por lo tanto necesitan ser aprendidos, tales como, la dinámica de los medios, cómo funcionan, su historia, sus usos y efectos dentro de la sociedad" (como se citó en Soriano Rodríguez, 2013, p. 22).

En un país como México, la educación en medios o alfabetización mediática tendrían que ser ejes transversales a lo largo de la formación educativa de sus ciudadanos. No obstante, como ya se ha apuntado, es algo ausente en la política educativa como en la discusión académica. El aprendizaje observado por niños, adolescentes, jóvenes y adultos ha sido resultado de la facilidad en el acceso a las TIC, como a las cualidades que hoy las caracterizan de usabilidad, accesibilidad, interactividad como su amigabilidad; por lo que pudiera asumirse que existen condiciones para orientar y acompañar en la educación mediática y la alfabetización digital de las actuales generaciones. Hay una tarea compleja que realizar por parte de las instituciones y autoridades educativas, los docentes y las familias mexicanas.

Tal cual se dice debajo de estas líneas:

El mundo educativo debe desembarcar, debe colonizar un nuevo continente desconocido desde las aulas, que es el continente de la comunicación... Hay que enseñar a educar las emociones que nos transmiten los medios, emociones que sin dejar de serlo integren la reflexión y la racionalidad. (Ambrós y Breu, 2011, p. 99) 
En esta tesitura, toca a la escuela generar condiciones para que el docente favorezca esa mediación.

\begin{abstract}
A los educadores profesionales habrá que formarles no solo para que adquieran ellos mismos un espíritu crítico y capacidad de reflexión en torno a la presencia, influencia y trascendencia de los medios en sus vidas, sino para que sean capaces de favorecer el desarrollo de esa misma actitud crítica en sus educandos. (Gutiérrez Martín y Torrego González, 2018, p. 22)
\end{abstract}

\title{
c. La "alfabetización mediática" y el poder de la comunicación
}

Comprender la alfabetización desde sus propias raíces (las letras griegas que la componen alpha y beta), así como el sufijo que define su intención, es reconocer el papel que juegan quienes intervienen en un proceso formativo, cuyo interés pedagógico es que una persona aprenda a decodificar y redactar un texto; acción que le permita adquirir una serie de habilidades y conocimientos para entender, interpretar, traducir o recrearse en un escrito.

Lo cierto es que, en estos tiempos, al hablarse de competencias para leer textos escritos, se debe hacer referencia a la dimensión sociotecnológica del acto de leer. Néstor García Canclini señala la necesidad de repensar las concepciones que se tienen de la lectura, al relacionarla con las habilidades para desmontar una gramática propia de lo tecnológico y digital: "Saber usar íconos de navegación, barras de desplazamientos, pestañas, menús, hipervínculos, funciones de búsqueda de texto, imágenes y músicas, mapas de sitios" (2014, p. 27). Alfabetizar hoy también es enseñar a desmontar narrativas, a decodificar paisajes, geografías y arquitecturas discursivas que recrean los medios de comunicación y las tecnologías como agencias de mediación.

El sujeto alfabetizado mediáticamente es aquel que puede identificar y decodificar el lenguaje audiovisual desde la perspectiva técnica, pero a la vez es capaz de interpretar el significado representado a través de una técnica, es decir qué imágenes, encuadres, textos encierran una realidad subjetiva deliberadamente creada. (Soriano Rodríguez, 2013, p. 27)

Vale entonces preguntarse si en México las instituciones educativas y sus comunidades docentes están concibiendo la alfabetización a partir del papel que juegan los MMC y las TIC como proveedores de textos, de códigos, de signos, de recursos digitales. Por ejemplo, las redes sociales y el servicio de mensajería han pasado a ser recursos comunicativos, tecnologías que contribuyen a pensar el mundo, a ejercer un estilo de vida, por lo que se deben comprender como parte de una "geografía mediática", en el entendido de que las prácticas y los hábitos que definen su empleo, reproducen prácticas y hábitos "de una comunidad, las cuales son parte de la construcción de su identidad y constituyen un elemento más de su distinción y cohesión entre sus miembros" (Padilla de la Torre, 2012, p. 158). 
En tales términos y por su eficacia para construir narrativas, puede asegurarse que el poder de las redes sociales es un hecho. Así se ha visto en España cuando la ciudadanía se volcó a las calles y decidió dar un giro en la política interna del país tras el posicionamiento político del movimiento $15 \mathrm{M}$ como consecuencia de los atentados en la estación de Atocha en Madrid; lo mismo la experiencia de la Primavera Árabe, en África y el Medio Oriente, tras la decisión de un hombre de prenderse fuego, al desencadenarse protestas ciudadanas que llevaron al derrocamiento de algunos gobiernos autocráticos. En México, con el movimiento \#YoSoy132 y \#LosQueremosVivos, cuando jóvenes hicieron visible su malestar ciudadano y exigieron una apertura democrática o la aparición de 43 estudiantes normalistas de Ayotzinapa desaparecidos.

Este tipo de empoderamiento ciudadano permite comprender la importancia de las tecnologías para la comunicación o difusión de contenidos así como para la organización colectiva, por lo tanto existen condiciones para pensar en una educación mediática (por lo instrumental) y ciudadana (por el sentido de pertenencia y civilidad), algo que pudiera potenciarse desde el concepto de educomunicación, al llamarse la atención sobre "la atención de la sociedad civil y de los poderes políticos respecto a los valores asociados a la ciudadanía", por lo que también se contribuiría a la "construcción de dicha ciudadanía" (Peruger-Camprino y Martínez-Cerda, 2016. p. 45).

En términos de las movilizaciones ciudadanas, plataformas como YouTube, redes sociales como Facebook, Instagram, microblogging como Twitter o el servicio de mensajería WhatsApp han sido medios privilegiados para convocatorias masivas, lo que demuestra el uso efectivo de las tecnologías, por lo tanto evidencia cierto tipo de educación. Ello, sin duda, se relaciona con prácticas y hábitos que visibilizan grados de alfabetización propia de una sociedad que participa, convoca y crea sus canales comunicativos, por lo que se puede reconocer una comunidad en la que se comparten "metas y prácticas dirigidas hacia una transformación comunicativa dinámica, activa y mediática" (Renés Arellano, 2013, p. 3).

No obstante, el resultado positivo en casos como los arriba mencionados también ha dado pie a la emergencia de grupos terroristas, movimientos fundamentalistas o experiencias humanas poco gratificantes, por ende, la urgencia para educar en medios, alfabetizar con conciencia y responsabilidad, de cara a una ciudadanía que dimensione lo heterogéneo y diverso, como el reconocimiento a los riesgos que supone el uso irreflexivo e irresponsable de las TIC. Tal como lo sostiene Huertas Bailén: "Las identidades grupales son cada vez más provisionales y las fronteras entre un grupo y otro son difusas", por lo que "las personas pueden pertenecer simultáneamente a varios grupos y es habitual trasladarse de uno a otro" (Huertas Bailén, 2002, p. 35). Ser un usuario de redes sociales no impide ser parte de una comunidad religiosa como tampoco asumir un avatar para reinventarse en los bajos mundos de internet o pertenecer a un grupo delincuencial, o reproducir información generada desde bots o trolls que esconden motivaciones 
ideológicas, políticas virulentas que, estratégicamente, se producen en contextos de coyuntura política o social. En un escenario así, niños, adolescentes y jóvenes, hombres y mujeres como consumidores de contenidos suelen desconocer quién está detrás de un mensaje, del tuit, de los likes, de información viralizada, por lo que urge contribuir a la prevención de malas prácticas y hábitos entre los usuarios de las TIC.

En México, como se ha mencionado, no son pocos los casos en que, a través de las redes sociales, se convoca a la ciudadanía a hacer visible su enojo: en el primer semestre del 2019, ciudadanos en Puebla y Veracruz emplearon Facebook y WhatsApp para convocar al linchamiento de presuntos delincuentes. En el caso de Veracruz, más tarde se supo que eran campesinos productores los que fueron quemados.

Tales eventos han puesto a prueba la fragilidad y vulnerabilidad, la falta de educación en medios por parte de una ciudadanía que se manifestó ante los rumores que corrieron en redes sociales. Si bien se vive una crisis de violencia e impunidad en México, resulta alarmante la forma en que la justicia por propia mano suele activarse al amparo de una certeza mal entendida, pues se confía demasiado en lo que se publica en Facebook o circula en WhatsApp.

De allí que la experiencia vivida en el puerto de Veracruz en agosto del 2011 marcara un punto de quiebre para dimensionar el rol que las redes sociales juegan al difundir información sin ser confirmada. Margarita Zires sobre aquella experiencia dice: "El ambiente de violencia que se vivió en 2011 en Veracruz es concebido y descrito en muchos mensajes de \#verfollow como un contexto de guerra velada, que se desconoce en el resto del país y que es ocultado por el gobierno estatal y los medios de comunicación locales" (2014, párr. 22).

Si bien puede comprenderse lo ocurrido por aquellos días, no se disculpa el hecho de que "una ola de rumores en la ciudad de Veracruz que versaban sobre ataques a escuelas y secuestros de niños por el crimen organizado" haya provocado una jornada de angustia entre los veracruzanos, al confiar a ciegas en los "rumores [que] circularon de manera oral, directa y personal, o mediada por teléfonos, así como de forma escrita a partir de mensajes por celulares y por las redes sociales" (2014, párr. 57). Incluso, se debe decir que en el campus Veracruz-Boca del Río, de la Universidad Veracruzana, las autoridades decidieron evacuar las facultades, entre ellas la de Ciencias de la Comunicación, sin haber confirmado ante las instancias o autoridad correspondiente la veracidad de aquellas versiones que circulaban en redes sociales.

Es importante subrayar: en México decenas de casos demuestran que el crimen organizado se aprovecha de la falta de seguridad e inocencia de muchos usuarios de redes sociales para sumarlos a sus causas, secuestrarlos, incluso, asesinarlos; las redes de trata de personas también han encontrado en internet un lugar para reproducir prácticas que laceran lo humano. En el caso de la ciudadanía, las movilizaciones 
vandálicas de enero del 2017, cuando usuarios de redes sociales fueron convocados en algunas ciudades para protestar contra el incremento de los combustibles, trajo como resultado el saqueo a negocios, muchos de los cuales terminaron en la quiebra.

En la ciudad de Veracruz, como en otras del estado, 48 horas bastaron para demostrar la barbarie de la que es capaz un ciudadano, un usuario de redes sociales. Los días 4 y 5 de enero del 2017, se realizaron más de cien robos, en los que tiendas, comercios, gasolineras fueron atracadas "por vándalos, organizaciones delictivas, civiles de colonias populares, pandilleros y estudiantes menores de edad, tras el incremento a los combustibles conocido como gasolinazo, impuesto por el gobierno federal" (Zavaleta, 2017, párr. 2). Tales eventos, fueron repetidos en los estados de Quintana Roo, Michoacán, Hidalgo y Tamaulipas.

Según la Asociación Nacional de Tiendas de Autoservicio y Departamentales (Antad), fueron 79 los establecimientos saqueados, además del cierre de 170 tiendas; disturbios derivados de las protestas por el incremento en los precios de las gasolinas (Expansión, 2017); coyuntura que aprovechó el crimen organizado para volver mostrar la vulnerabilidad de los usuarios de redes sociales.

Frente a experiencias y prácticas mediáticas como estas, se confirma el poder de convocatoria y seducción de las tecnologías digitales, un fenómeno que demuestra en la práctica la facilidad para producir, consumir y distribuir contenidos; pero también la poca responsabilidad y ausencia de criticidad con que se responde a ellas, un uso que no siempre discrimina o confirma la veracidad de la información; analfabetismo que confirma la fragilidad de muchas de las prácticas y hábitos que se tienen en México. Si bien es cierto, como dice Soriano Rodríguez, que "internet ha contribuido a la interacción de la Sociedad Red al convertirse en un medio de comunicación", que, a diferencia de medios como la TV, la radio, la prensa o el cine, "permite el libre intercambio de ideas, las cuales, como medio de comunicación pueden llegar a modelar concepciones e ideas de quien los lee o escucha..." (Soriano Rodríguez, 2013, p. 31), también lo es que en muchas de las prácticas de consumo o para producir y circular contenidos se revela un analfabetismo que se debe atender desde los ámbitos educativos, formales e informales.

\section{d. De la domesticación a la alfabetización mediática y digital en México}

En México, se informa que $92 \%$ de la población posee un teléfono inteligente, $79 \%$ computadora personal, $50 \%$ tablet, y se destaca que " $87 \%$ de ellos se conecta a internet a través de su teléfono inteligente, $75 \%$ por computadora y $38 \%$ por tablet" (Televisa, IAB México y Kantar Millwar Brown, 2018, p. 13). Estos números resultan significativos cuando se dice que el $79 \%$ declara que las aplicaciones que más emplea son las redes sociales, destaca "Facebook con un $97 \%$, YouTube con $70 \%$, Twitter con $59 \%$, Google+ 59 $\%$, Instagram con 44 \%" (Televisa, IAB México y Millwar Brown, 2016, p. 33). 
Los internautas señalan que un $93 \%$ consume contenidos, destacan que "el $67 \%$ ve fotos, el $46 \%$ lee publicaciones de las personas que sigue", mientras que el $87 \%$ se declara productor de información. En este rubro los números arrojan los siguientes resultados: "usar chat de la red social $51 \%$, enviar inbox $43 \%$, subir fotos $41 \%$, publicar comentarios $35 \%$, compartir información, videos o fotos de otros usuarios $34 \%$ " (Televisa, IAB México y Kantar Millwar Brown, 2018, p. 32). Con estos datos, se confirma el lugar que ocupan las tecnologías en la vida de los mexicanos, de los cuales 72,7 millones invierten un promedio de 2,2 horas diarias como usuarios de redes sociales.

Esto trae como resultado la comprensión del porqué de lo que ha ocurrido en algunas experiencias mexicanas que se destacan por la visibilidad de grupos que abanderan causas ciudadanas, pero también de esos miles de niños, adolescentes, jóvenes, incluso adultos que, sin asumir una postura crítica, se suman a la viralización de contenidos que -en ocasiones- vulneran la integridad de las personas, o son presas y rehenes de malas prácticas que suelen encabezar quienes han encontrado en internet, las redes sociales o el servicio de mensajería la oportunidad para distribuir noticias falsas o implementar estrategias propias de redes criminales.

He aquí la pertinencia de volver al vínculo entre comunicación y educación para reconocer la necesidad de que, en México y, particularmente, en Veracruz, se implementen políticas educativas encaminadas a la educación mediática y la alfabetización digital, pues si bien la ciudadanía cuenta con habilidades para el uso de las TIC, falta formarla en su mejor empleo. Como apunta Couldry, este tipo de competencias son "disposiciones y actitudes, que permiten la acción cotidiana orientada hacia los medios o en relación con ellos" (como se citó en Valdivia-Barrios, Pinto-Torres y Herrera-Barraza, 2018, p. 3), pero su uso no basta, hay que hacerlo con conciencia y desde una postura crítica.

Por ende, una alfabetización digital ciudadana resignificaría el empleo de ellas entre los usuarios mexicanos. Los autores consultados apuntan la necesidad de reflexionar y discutir sobre alfabetización mediática o los fenómenos propios del aprendizaje y los lenguajes, ya que "por medio de ellos se puede dar cuenta de las particularidades que presentan los escenarios y tecnologías digitales, y los nuevos medios, para avanzar en el conocimiento de las prácticas mediáticas y las transformaciones sociales que ellas suponen" (2018, p. 12).

Se dice que la educomunicación provee al usuario de criterios razonables para que las tecnologías sigan favoreciendo relaciones sociales, pero también de medios para contribuir al crecimiento personal, donde lo lúdico y estético siga siendo parte de sus formas de entretenimiento y socialización, pero donde prevalezca un uso crítico y consciente de un usuario sabedor de los componentes políticos, ideológicos, económicos y de riesgo que hay detrás de sus narrativas (Espinosa Mijares, 2009). Buitrago, Ganga y 
García Matilla aseguran que "la enseñanza de las TIC requiere nuevos enfoques innovadores que sean capaces de diagnosticar nuevos problemas y generar estrategias para su resolución" (2015, p. 32).

La sociedad mexicana, las autoridades educativas, las familias y los propios usuarios deben repensar el tipo de uso, pasar de una domesticación acrítica a un empleo consciente y generador de experiencias sociales, culturales, educativas, personales, incluso políticas, que reconozcan lo heterogéneo, diverso y diferente; así como el valor que tienen las tecnologías para fortalecer una cultura democrática, donde prevalezcan las libertades del individuo, contribuyendo significativamente al empoderamiento ciudadano "mediante estrategias pedagógicas, discursivas, tecnológicas y de producción de dispositivos que fomenten la libertad de expresión" (Grijalva-Verdugo y Moreno Candil, 2017, p. 30) como valores intrínsecos de una competencia mediática alfabetizada; lo que favorecería que dimensionen lo que puede estar detrás de una información que comparten, de una imagen que viralizan, de un meme que distribuyen, de un amigo al que aceptan, de un like que pone en riesgo la vida y dignidad de una persona.

Manuel Castells observa que, en la historia social de todo desarrollo tecnológico, la relevancia de una u otra tecnología está dada por su aparición, particularmente por la forma en que la gente la usa, por "la apropiación que de la tecnología hacen los individuos y los colectivos para satisfacer sus necesidades y de sus culturas" (2012, p. 470). En México hay evidencia suficiente para reconocer el papel que juegan las TIC, al facilitar la comunicación en sus diversas modalidades. El propio Castells sostiene que "la capacidad interactiva del nuevo sistema de comunicación da paso a una nueva forma de comunicación, la autocomunicación de masas, que multiplica y diversifica los puntos de entrada en el proceso de comunicación" (2012, p. 188). En este texto, se ha hecho referencia a eventos ciudadanos en los que esto queda demostrado, pero también se han mencionado eventos criminales o delincuenciales, que vulneran a esta sociedad y a la dignidad de las personas.

Estas experiencias revelan la necesidad de un "mapa ético para navegar por las autopistas de la inmensa información de nuestro mundo" (Ambrós y Breu, 2011, p. 100), por lo que urge una educación mediática y digital que favorezca el desarrollo de un pensamiento crítico, donde resulta oportuno aclarar "que la competencia mediática es una habilidad adquirida por las audiencias diferenciadamente y en relación al contexto, escolaridad, edad, entre otros factores socioculturales" (Grijalva-Verdugo y Moreno Candil, 2017, p. 33); por lo que, si queremos que los ciudadanos se hagan de un nuevo protagonismo en el uso de las TIC, es necesario que adquieran habilidades y conocimientos propios de una alfabetización mediática y digital. Y este es el gran pendiente en México. 


\section{REFLEXIONES FINALES}

Apenas en este 2019, la circulación de fake news difundidas en redes sociales relacionadas con "robachicos", "robo de órganos" o "secuestradores" en los estados de Yucatán, Durango, Jalisco y Sinaloa provocó una psicosis ciudadana, sin dejar de señalar los linchamientos contra supuestos delincuentes que han tenido lugar en algunas poblaciones de los estados de Puebla y Veracruz (Molina Carrillo, 2016), fenómeno cada vez más común que lleva a pensar en la necesidad de una educación centrada no solo en las destrezas tecnológicas, sino también en el conocimiento de cómo se produce contenido y quiénes pueden hacer uso de él, como sus intenciones.

En México, si bien pudiera haber comunidades académicas interesadas y ocupadas de promover la alfabetización mediática y digital, en términos reales suele estar ausente, por lo que se puede decir, está invisibilizada como derecho humano y principio pedagógico. La relación entre los medios de comunicación y sus públicos siempre ha sido de tensión y subordinación. No obstante, el desarrollo tecnológico ha facilitado que el emisor y el receptor tengan un rol diferente.

Sin embargo, eso no exime a la educación de asumir una responsabilidad que le compete: educar al ciudadano del siglo xxI. Antes que prescribir, se deben tender puentes entre la educación y la vida cotidiana, para que los medios de comunicación en sus múltiples narrativas sean leídos desde lo razonable, crítico y creativo. Por ende, "sería bueno que el sistema educativo se planteara explicar con una orientación más práctica aspectos estéticos concretos siempre útiles para la vida", lo que permitiría que los públicos usuarios comprendan lo "que entraña construir narrativas que pueden resultar veraces y convincentes para el público y sepan apreciar el trabajo de los profesionales de la creación" (Gutiérrez Jon Dornaleteche y García Matilla, 2015, p. 75); pero también de quienes detrás de un mensaje, tienen objetivos poco claros o de alto riesgo para el ciudadano. Al respecto, Ignacio Aguaded y Luis M. Romero-Rodríguez sostienen:

El riesgo de la desinformación en internet, en especial en las redes sociales, subyace en la propia interactividad y permeabilidad del trinomio receptor-productordifusor de contenidos - prosumo- con que está compuesta la información en línea, siendo casi imposible para aquellos carentes de suficientes niveles de competencia digital, informacional y comunicativa, distinguir entre información, rumores y desinformación. (2015, p. 47)

Es por ello que cualquier docente, padre de familia, niño, adolescente o joven que hoy tiene acceso a una tecnología, si bien a un clic tiene todo el conocimiento, las fórmulas y medios para el entretenimiento y la diversión, también son sujetos vulnerables y muchas veces inconscientes en el tipo de uso que suelen dar a las tecnologías, particularmente a las redes sociales. Toca entonces a la educación, a las familias, a padres y madres guiar en una educación que facilite el desarrollo de una alfabetización mediática y digital. En un 
país como México, en un estado como Veracruz, esto es apremiante porque la sociedad vive en permanente riesgo y vulnerabilidad ante un analfabetismo mediático tecnológico, como consecuencia de la falta de políticas educativas orientadas a la educomunicación.

Es urgente que las instituciones educativas generen políticas de formación y acompañamiento en materia de medios y por una cultura digital. Que las relaciones establecidas alrededor de las TIC den la oportunidad a los estudiantes "de acceder a las habilidades y competencias que necesiten, del nivel de control que les permita ejercer sobre el proceso..." (Ambrós y Breu, 2011, p. 183). Aquí, los profesores deben ser facilitadores y mediadores de una alfabetización que se entienda en el contexto de la sociedad del conocimiento.

No dudemos, las tecnologías como herramientas para innovar lo educativo pasan también por la configuración de un ambiente de aprendizaje centrado en la educación mediática y la alfabetización digital, lo que hace más complejo el fenómeno educativo, más difícil el rol que tienen los centros escolares. Como dice Di Mele, "el mundo reservado y exclusivo de la educación se ha vuelto permeable al mundo exterior, es decir, ahora profesores, alumnos y familias son algunos de los nodos de una red que se extiende fuera de las paredes escolares" (2017, pp. 81-82), por lo que deben generarse sinergias de colaboración, pero, sobre todo, partir del reconocimiento de la complejidad y la necesidad de una corresponsabilidad para enfrentar el reto de educar mediática y digitalmente a una generación que vive interpelada y sometida a narrativas que necesitan decodificar con sapiencia.

Ver a un adolescente compartir una selfie en su muro es una práctica común en el uso de redes sociales como Facebook, Instagram o WhatsApp, pero no tener conciencia de los riesgos o usos que esto supone vulnera a los usuarios. Lo mismo a quien sin pensarlo se fotografía en ropa interior o acepta la amistad de un desconocido, como aquel que ante un meme no reconoce actos velados de discriminación y estigmatización que se viralizan.

Como puede reconocerse, son los jóvenes quienes más emplean las redes sociales, uso que aprenden por ensayo y error, cuyo resultado suele ser producto de la falta de conciencia que caracteriza su uso, por lo que "no tener en cuenta los peligros señalados les puede acarrear a los jóvenes usuarios virtuales el padecimiento de agresiones virtuales puntuales y, en el peor de los casos, de violencia virtual continuada o ciberacoso" (Tejada Garitano, Castaño Garrido y Romero Andonegui, 2019, p. 5). García Galera y Fernández Muñoz sostienen que "cualquier acción del carácter que sea y cualquiera que sea la finalidad que busque encuentra en las redes sociales el sitio para su difusión inmediata, en tiempo real, acompañada por la interactividad y unas infinitas posibilidades de intercomunicación" (2017, p. 136). 
Con todo lo anterior, redes sociales como Facebook terminan por ser espacios privilegiados para socializar y compartir información en audio, imagen, video o texto por parte de los mexicanos, especialmente jóvenes que han encontrado en ellos "una forma narcisista de expresión, de exhibición de la vida privada y de pasatiempo trivial", mientras que, para otros, son "la manifestación máxima de libertad de expresión y expansión de vínculos, amistades y conocidos" (Pogliagui, 2015, p. 49).

Si bien es de reconocer que cada vez hay más ciudadanos comprometidos y dispuestos a expresar sentimientos y puntos de vista sobre lo que vive y le ocurre a su país como al propio mundo, donde las redes sociales son medios para opinar, para señalar injusticias, clamar contra la violencia y manifestar solidaridad, también dan cabida a otros relatos, a experiencias que tendrían que doler, como son los secuestros o extorsiones facilitados por el tipo de información publicada en Facebook o Instagram, las estafas telefónicas, la trata de personas por internet, la distribución de contenidos sexuales en redes sociales (del sexting a los pack), pero pareciera que en Veracruz, México, muchas de estas prácticas se han naturalizado, vulnerando a su sociedad; en todo caso, exhibiendo grados de analfabetismo mediático o digital. Para contrarrestarlo, se debe educar y alfabetizar en el consumo de contenidos mediáticos y digitales, en una conciencia crítica frente a las narrativas que definen el paisaje contemporáneo, en donde los medios de comunicación y las tecnologías, especialmente las redes sociales, son agencias claves y medios privilegiados para su configuración.

\section{REFERENCIAS}

Acosta-Silva, D. A. (2017). Tras las competencias de los nativos digitales: avances de una metasíntesis. Revista Latinoamericana de Ciencias Sociales, Niñez y Juventud, 1 (15), 471-489. http://dx.doi.org/10.11600/1692715x.1513014062016

Aguaded, I. y Romero-Rodríguez, L. M. (2015). Mediamorfosis y desinformación en la infoesfera: Alfabetización mediática, digital e informacional ante los cambios de hábitos de consumo informativo. EKS, 16(1), 44-57. Recuperado de http:// rabida.uhu.es/dspace/bitstream/handle/10272/10420/Mediamorfosis. pdf?sequence $=2$

Amayuela Mora, G. (2017). Comunicación y su relación con la educación en el contexto universitario. Alternativas en psicología, 5(3), 8-19. Recuperado de https://www. alternativas.me/attachments/article/119/Comunicaci\%C3\%B3n\%20y\%20 su $\% 20$ relaci\%C3\%B3n\%20con\%20la\%20educaci\%C3\%B3n\%20en $\% 20$ el $\% 20$ contexto\%20universitario.pdf

Ambròs, A. y Breu, R. (2011). Educar en medios de comunicación. La educación mediática. 10 ideas claves. Barcelona: Grao. 
Balart Carmona, C. y Cortés Fuentealba, S. (2018). Una mirada histórica del impacto de las TIC en la sociedad del conocimiento en el contexto nacional actual. Contextos: Estudios de humanidades y ciencias sociales, (41), 1-19. Recuperado de https:// dialnet.unirioja.es/servlet/articulo?codigo $=6529351$

Buitrago, A., Ganga, M. y García Matilla, A. (2015). La competencia mediática en el contexto de la educomunicación. En Buitrago, A. Navarro, E. y García Matilla, A. (Eds.). La educación mediática y los profesionales de la comunicación, 19-36. España: Gedisa editorial.

Bustamante, E. (2017). La comunicación desde la cultura, la cultura de la comunicación. En: De Moragas, M.; Terrón, J. L. y Rincón, O. (Eds.), De los medios a las mediaciones de Jesús Martín Barbero, 30 años después, 103-106. InCom-UAB Publicacions, 14. Bellaterra: Institut de la Comunicació, Universitat Autònoma de Barcelona.

Castells, M. (2012). Comunicación y poder. México: Siglo XXI.

Cepal. (2016). La nueva revolución digital. Del internet del consumo al internet de la producción. México: Cepal/ONU/ELAC.

Coll, C. (2008). Aprender y enseñar con las TIC: expectativas, realidad y potencialidades. Boletín de la Institución Libre de Enseñanza, (72), 17-40. Recuperado de http:// www.ub.edu/ntae/dcaamtd/Coll_en_Carneiro_Toscano_Diaz_LASTIC2.pdf

Corona Berking, S. (18 de noviembre del 2015). Escasa la educación mediática en México, dicen especialistas. Centro universitario de ciencias sociales y humanidades. Recuperado de http://www.cucsh.udg.mx/noticia/escasa-la -educacion-mediatica-en-mexico-dicen-especialistas

De Fontcuberta, M. (2001). Comunicación y educación: una relación necesaria. En: Cuadernos de información, (14), 140-147. Recuperado de https://dialnet.unirioja. es/servlet/articulo?codigo $=2938303$

Di Mele, L. (2017). Complejidad e innovación en relación con la alfabetización mediática y la información. En Pérez Tornero, J. M., y Martire, A. (Eds.). Educación y nuevos entornos mediáticos. El desafío de la innovación, 77-90, Barcelona: Editorial UOC.

Espinosa Mijares, 0. (2009). ¿Tecnología de lo público? En Castro Merrifield (Coord.). Comunicación, tecnología y sociedad. México: Universidad Iberoamericana.

Expansión (4 de enero de 2017). 79 tiendas saqueadas y 170 cerradas por disturbios: Antad. Expansión. Recuperado de https://expansion.mx/empresas/2017/01/04/79tiendas-saqueadas-y-170-cerradas-por-disturbios-antad.

Fernández-García, N. (2017). Fake news: una oportunidad para la alfabetización mediática, Nueva Sociedad, 93(32), 62-77. Recuperado de http://www.iade.org. ar/system/files/5.tc_fernandez_269_0.pdf 
Fundación Telefónica. (2017). EduSapiens. Una guía para diseñar experiencias creativas en el aula, 2. Edición. Madrid: Fundación Telefónica.

García Galera, M. del C. y Fernández Muñoz, C. (2017). Las redes sociales como medios para la participación de las nuevas generaciones, En Pérez Tornero, J. M., y Martire, A. (Eds.) Educación y nuevos entornos mediáticos. El desafío de la innovación, 126-140. Barcelona: Editorial UOC.

Gobierno del Estado de México (2019). ¿Qué es la extorsión? Conocer y entender los fenómenos delictivos, te permitirá contar con herramientas de prevención y autocuidado. Recuperado de https://www.gob.mx/policiafederal/es/articulos/ que-es-la-extorsion?idiom=es

Gómez, E. (22 de febrero del 2019). Mueren 4 hombres linchados en Veracruz. La Jornada. Recuperado de https://www.jornada.com.mx/ultimas/2019/02/22/muerencuatro-hombres-linchados-en-veracruz-780.html

Grijalva-Verdugo, A. A. y Moreno-Candil, D. (2017). Empoderamiento social en contextos violentos mexicanos mediante la competencia mediática. Comunicar, 25(53), 29-38. https://doi.org/10.3916/C53-2017-03

Gutiérrez Jon Dornaleteche, A. y García Matilla, A. (2015). La opinión de los profesionales de la comunicación audiovisual. En Buitrago, A. Navarro, E., y García Matilla, A. (Eds.). La educación mediática y los profesionales de la comunicación, 53-86. Comunicación. España: Gedisa editorial.

Gutiérrez Martín, A.G. y Torrego González, A. (2018). Educación mediática y su didáctica. Una propuesta para la formación del profesorado en TIC y medios. Educación mediática y formación del profesorado, 91(32-1), 15-27. Recuperado de https:// dialnet.unirioja.es/servlet/articulo?codigo $=6441409$

Huertas Bailén, A. (2002). La audiencia investigada, Colección Estudios en Comunicación. Barcelona: Editorial Gedisa.

Li, Y. y Ranieri, M. (2010). Are «digital natives» really digitally competent?: A study on Chinese teenagers: Chinese teenagers' digital competence. British Journal of Educational Technology, 41(6), 1029-1042. doi:10.1111/j.1467-8535.2009.01053.x

Martín-Barbero, J. (2003). De los medios a las mediaciones. Comunicación, cultura y hegemonía. Colombia: Editorial Gustavo Gili/Andrés Bello.

Méndez Forssell, A. (9 de agosto del 2017). La alfabetización mediática, o ¿por qué educar a las audiencias a defenderse a sí mismas? Revista Nexos, (9). https://educacion. nexos.com. $\mathrm{mx} / \mathrm{p}=622$

México, cuarto lugar a nivel mundial en el uso de redes sociales. (18 de enero del 2018). Excelsior. Recuperado de https://www.excelsior.com.mx/hacker/ 2018/01/18/1214650 
Molina Carrillo, J. G. (12 de noviembre del 2016). Los linchamientos en Puebla a la alza. Milenio. Recuperado de https://www.milenio.com/opinion/juliangerman-molina-carrillo/sociedad-derechos-humanos/los-linchamientos -en-puebla-a-la-alza

Notimex. (18 de octubre del 2016). Uso de internet ha incrementado el índice de menores desaparecidos. Publimetro. Recuperado de https://www.publimetro.com.mx/mx/ noticias/2016/10/18/internet-incrementado-indice-menores-desaparecidos. html

OCDE (2017). Panorama de la educación 2017. Indicadores de la OCDE. España: Fundación Santillana.

OEI (2009). Los desafíos de las TIC para el cambio educativo. Madrid: Fundación Santillana.

Padilla de la Torre, M. R. (2012). Geografías ciudadanas y mediáticas. México: Universidad de Aguascalientes.

Peruger-Camprino, M. y Martínez-Cerda, J. F. (2016). Alfabetización mediática en Brasil: experiencias y modelos en educación no formal. Comunicar, 24(49), 38-49. http:// dx.doi.org/10.3916/C49-2016-04

Pogliagui, L. (2015). Estudiantes 2.0: jóvenes, violencia y Facebook. Caleidoscopio, (33), 45-64. doi:10.33064/33crscsh558

Policía Federal. (2019). ¿Qué es la extorsión? USECIM International Magazine. Recuperado de https://usecim.net/2019/05/03/que-es-la-extorsion/

Quiroz, M. T. (1997). Propuestas para la comunicación y la educación. Comunicar, 5(8), $31-48$.

Ramírez García, A., Renés Arellano, P. y González Fernández, N. (2016). La competencia mediática a través de los contenidos curriculares en la etapa de educación primaria en España. Educação \& Sociedade, 136(37), 821-838. http://dx.doi. org/10.1590/es0101-73302016128894

Renés Arellano, P. (2013). Educación mediática en la sociedad actual. Edmetic, 2(2), 3-7. doi:10.21071/edmetic.v2i2.2875.

Secretaría de Educación Pública (SEP). (2017). Modelo educativo para la educación obligatoria. Educar para la libertad y la creatividad. México: Secretaría de Educación Pública.

Soriano Rodríguez, A. M. (2013). Educación mediática 2.0. Diálogos, (12), 17-43. https://doi. org/10.5377/dialogos.v0i12.2192

Steve, 0. (24 de septiembre del 2018). Extorsiones telefónicas en México crecieron en un 90 por ciento del 2012 al 2018. Xataca. Recuperado de https://www.xataka.com.mx/ seguridad/extorsiones-telefonicas-mexico-crecieron-90-ciento-2012-al-2018 
Tedesco, J. (2008). Las TIC en la agenda de la política educativa. En J. Tedesco, N. Burles, E. Martín, P. Hepp, J. Morrissey, J. Duro et al., Las TIC: del aula a la agenda política, 23-30. Buenos Aires: UNICEF. Recuperado de https://www.oei.es/historico/pdfs/ las_tic_aula_agenda_politica.pdf

Tejada Garitano. E., Castaño Garrido, C. y Romero Andonegui, A. (2019). Los hábitos de uso en las redes sociales de los preadolescentes. Revista Iberoamericana de Educación a Distancia, 22(2), 119-133. http://dx.doi.org/10.5944/ried.22.2.23245.

Televisa, IAB México y Millwar Brown (2016). Estudio de consumo de medios y dispositivos entre internautas mexicanos.

Televisa, IAB México y Kantar Millwar Brown (2018). Estudio de consumo de medios y dispositivos entre internautas mexicanos.

Unesco (s/f). Programa de formación en alfabetización mediática e informacional destinado a los docentes. Francia: Unesco.

Unesco (2011). Alfabetización mediática e informacional. Currículum para profesores. Francia: Unesco .

Unesco (2013). Enfoques estratégicos sobre las TICS en Educación en América Latina y el Caribe. Santiago de Chile: Unesco.

Valdivia-Barrios, A., Pinto-Torres, D. y Herrera-Barraza, M. (2018). Alfabetización mediática y aprendizaje. Aporte conceptual en el campo de la comunicación-educación. Revista Electrónica Educare, 2(22), 1-16. http://dx.doi.org/10.15359/ree.22-2.8

Vázquez, R. (23 de agosto del 2018). Los desafíos de la educación digital en México. Forbes México. Recuperado de https://www.forbes.com.mx/ los-desafios-de-la-educacion-digital-en-mexico/

Winocur, R. (2009). Robinson Crusoe ya tiene celular, colecc. Diseño y Comunicación. México: UAM/Siglo XXI.

Zavaleta, N. (9 de enero del 2017). Los saqueos en Veracruz: orquestados, organizados, sospechosos... Reportaje especial. Proceso.com.mx. Recuperado de https://www.proceso.com.mx/469269/los-saqueos-en-veracruz-orques tados-organizados-sospechosos

Zires, M. (2014). Violencia, redes sociales y procesos de subjetivación política: El caso de \#verfollow en Veracrúz, México. Argumentos, 27(75), 119-144. doi:10.1111/j.1083-6101.1997.tb00075.x/]. 